\title{
El castillo de Coca y los Fonseca. Nuevas aportaciones y consideraciones sobre su arquitectura
}

\author{
Luis VASAllo TORANZO \\ Universidad de Valladolid \\ Departamento de Historia del Arte \\ vasallo@fyl.uva.es
}

Recibido: 11-02-2014

Aceptado: 24-06-2014

\section{RESUMEN}

La documentación inédita sobre el castillo de Coca permite acotar las fechas de su construcción, conocer los maestros que la llevaron a cabo (Maestre Farax y Alí Caro para la fortaleza del siglo XV, y Diego Rodríguez y Juan de Ruesga para el interior palaciego del XVI) y distinguir con precisión las dos campañas promovidas por los hermanos Alonso y Antonio de Fonseca. Igualmente, la introducción de columnas y ventanas de mármol genovés por parte de Antonio en un momento muy temprano acrecienta el interés del edificio.

Palabras clave: Castillo, Alí Caro, Maestre Farax, Juan de Ruesga, Diego Rodríguez, Génova, mármol.

\section{The castle of Coca and the Fonseca. New contributions and considerations about its architecture}

\begin{abstract}
Unpublished papers about the Coca castle let us determine the dates of its construction, know the masters who conducted it (Master Farax and Alí Caro for the fortress in the XV century, and Diego Rodríguez and Juan de Ruesga for the palace inner part in the XVI century) and precisely distinguish the two campaings pioneered by Alonso and Antonio de Fonseca brothers. It also gives us notice of the insertion of genovese marble windows and columns by Antonio at an early time, wich increases the interest of the building.
\end{abstract}

Key words: Castle, Alí Caro, Master Farax, Juan de Ruesga, Diego Rodríguez, Genoa, Marble. 
“...que éste es uno de los [edificios] insines de toda España; y de su calidad y manera, el mejor. Y quien le hizo, le fundó por prençipal cosa de su estado".

Rodrigo Gil de HonTAÑóN ${ }^{1}$

El hallazgo de un pleito entre Mayor de Fonseca, hija de Alonso de Fonseca, promotor del Castillo de Coca, y los herederos de su tío Antonio de Fonseca por el coste de la obra de la fortaleza ${ }^{2}$, proporciona nuevos datos que amplían y completan la información existente sobre el edificio, pero también modifican en buena medida algunas cuestiones sustanciales. Una de ellas es la identidad del primer maestro del edificio, que no fue Alí Caro, sino Maestre Farax; otra, la posibilidad de aclarar la personalidad de los responsables de la reforma palaciega llevada a cabo por Antonio a principios del XVI, donde intervinieron el tardogótico Juan de Ruesga y el albañil sevillano Diego Rodríguez, quienes diseñaron un patio de tres pandas, donde se integraban mármoles genoveses y adornos de yesos y azulejos sevillanos.

Fue Cooper el primero en desvincular el castillo de Coca del arzobispo de Sevilla Alonso de Fonseca ${ }^{3}$. La decisión de este príncipe de la Iglesia de no edificar una fortaleza en su villa segoviana, mantenida contra la opinión de su hermano Fernando y de su sobrino Alonso, los herederos de su mayorazgo, se demostró acertada cuando la localidad rechazó las arremetidas de las tropas de Enrique IV en el cerco de $1464^{4}$.

Fallecido el prelado en 1473, su sobrino, llamado también Alonso de Fonseca, tuvo que retrasar el inicio de la construcción más de una década, hasta ver confirmada la herencia del arzobispo, que le era contestada por algunos poderosos y familiares ${ }^{5}$. En torno a 1485 Alonso de Fonseca decidió comenzar las obras. El sitio elegido, situado al suroeste de la villa, lo ocupaban unos azafranales propiedad de unos judíos, lindantes con un tramo en ángulo de la cerca, donde se situaba la puerta de Santiuste ${ }^{6}$. Los terrenos fueron cuidadosamente elegidos, pues se localizaban entre el cauce del río Voltoya y el del regato que desde la localidad desagua en él, de manera que para la ejecución de parte de la enorme y profunda cava que rodea el castillo se aprovecharon los desniveles creados por dichas cuencas, que fueron cerradas por taludes de tierra chapados con ladrillo ${ }^{7}$. Además, la presencia de la antigua muralla permitía,

\footnotetext{
1 Declaración de Rodrigo Gil de Hontañón en la tasación del castillo de Coca el 25-8-1547. Archivo de la Real Chancillería de Valladolid (ARChV), Pleitos Civiles, Varela (F), C. 1731-5.

2 ARChVa, P1. Civiles, Ceballos Escalera (F), C. 1122-1 a 1125-1.

3 E. COOPER, Castillos señoriales en la corona de Castilla, vol. I.1, Junta de Castilla y León, Salamanca, 1991, pp. 182 y ss.; y ello a pesar del permiso concedido por Juan II para construir una fortaleza en 1453, J.M. PITA ANDRADE, "El castillo de Coca reconstruido", Goya, 28, 1959, p. 212.

4 A. de PALENCIA, Crónica de Enrique IV, t. I, Biblioteca de autores españoles, 257, Madrid, 1973, pp. 154-7. También, ARChV, Pl. Civiles, Alonso Rodríguez (D), 16-1, 1ª pieza, declaración de Cristóbal de Toledo.

5 ARChV, Pl. Civiles, Alonso Rodríguez (D), C. 15-1 a 18-1.

6 ARChV, Pl. Civiles, Ceballos (F), C. 1124-1, $2^{\mathrm{a}}$ pieza. Sobre la cerca de Coca, J. F. BLANCO GARCÍA, "Fortificación y organización del espacio de una villa segoviana a comienzos del siglo XVI", I Congreso de castellología ibérica, Palencia, 1994, pp. 237.

7 E. COOPER, ob. cit., p. 177.
} 
como ya se había hecho en las fortalezas vecinas de Medina del Campo y Arévalo, aprovechar parte de la misma -de la que aún quedan restos visibles en la esquina sureste del foso ${ }^{8}$ - para levantar algunos paños del recinto interior. Así ocurrió, por ejemplo, con el meridional, donde en antiguas fotografías se aprecia el aparejo de piedra de la muralla, oculto hoy en día bajo un forro de ladrillo aplicado durante la última restauración ${ }^{9}$.

Alonso de Fonseca comenzó a acumular los materiales necesarios durante tres o cuatro años ${ }^{10}$. Una vez recogida la piedra para los fundamentos y el ladrillo para los muros se comenzó la obra. Eso ocurrió hacia 1488, cuando toda la villa acudió a la colocación de la primera piedra ${ }^{11}$. Desde entonces y hasta su muerte, con la sola excepción de los casi cuatro años en que ejerció el cargo de capitán de los continos y tuvo que residir en la Corte ${ }^{12}$, Alonso de Fonseca dedicó sus mayores esfuerzos a la consecución de la obra. Durante los más de 15 años que duraron los trabajos bajo sus órdenes (casi 20 si se contabilizan los destinados a acumular materiales antes de 1488), se gastaron anualmente más de 400.000 maravedís, a veces hasta $600.000^{13}$.

Las campañas abarcaban siete u ocho meses, de marzo a octubre, durante los que se labraba seis días a la semana, de lunes a sábado. Según las cuentas de la obra -se han conservado las de abril a junio de 1500-, los gastos diarios superaban de ordinario los 2.000 maravedís, y alcanzaban a veces los 3.000, lo que sumaba alrededor de 60.000 maravedís mensuales ${ }^{14}$.

La obra se comenzó por el ángulo sureste del recinto interior. Aprovechando la cerca se levantaron los muros meridional y occidental, continuándose la obra por los lados norte y este hasta completar el cuadrángulo. En las esquinas se ubicaron sendas torres angulares. En la sureste se levantó la denominada del Ladrón; en la suroeste, la de la Fuente o del Caño; en la noroeste, donde se situaba la citada puerta de San-

8 J. F. BLANCO GARCÍA, “Fortificación y organización del espacio...”, p. 239.

9 La foto ha sido publicada por F. RODRÍGUEZ MARTÍNEZ y D. RUBIO GALINDO, El castillo de Coca. La historia, el arte, la leyenda, Segovia, 2013, p. 25.

10 ARChV, Pl. Civiles, Ceballos (F), C. 1122-1, 2a pieza, declaración de Francisco Muñoz. Ver también el testimonio de Andrés de Navasdoro.

11 “...e seyendo ésta que depone niña de poca hedad oyó desir a su padre e a su madre cómo avyan ydo ellos e otras muchas personas de la dicha villa de Coca a ver poner la primer pyedra que se puso en la fortaleza de la dicha vylla de Coca". ARChV, Pl. Civiles, Ceballos (F), C. 1123-1, $5^{\mathrm{a}}$ pieza, testimonio de Francisca de Montalvo. Sobre las ceremonias del asentamiento de la primera piedra, L. ARCINIEGA GARCÍA, "La ceremonia de la primera piedra en España: símbolo y memoria”, en V. MÍNGUEZ (ed.), Las artes y la arquitectura del poder, Castelló de la Plana, 2013, pp. 431-461.

12 Alonso de Fonseca fue el primer capitán de los "continos", cuerpo de caballería creado por los Reyes Católicos en 1495 como guardia personal. Fonseca ejerció dicha capitanía entre 1495 y 1498. R. M. MONTERO TEJADA, "Los continos 'hombres de armas' de la casa real castellana (1495-1516): una aproximación de conjunto", Boletín de la Real Academia de la Historia, CXCVIII, 1 (2011), pp. 103-130.

13 ARChV, Pl. Civiles, Ceballos (F), C. 1122-1, 5 $5^{\text {a }}$ pieza.

14 Se aportaron al pleito habido entre Juan de Fonseca (hijo de Antonio de Fonseca) y Mayor de Fonseca (hija de Alonso de Fonseca) por haber recibido ésta, en vida de Antonio de Fonseca, más de los diez cuentos de maravedís en que fueron tasadas las obras de la fortaleza de Coca a la muerte de Alonso. ARChV, Pl. Civiles, Ceballos (F), C. 1125-1, $2^{\mathrm{a}}$ y $3^{\mathrm{a}}$ piezas. 
tiuste $^{15}$, la llamada entonces de la Prisión y posteriormente de Pedro Mata; y en la noreste, la del Homenaje (Fig. 1).

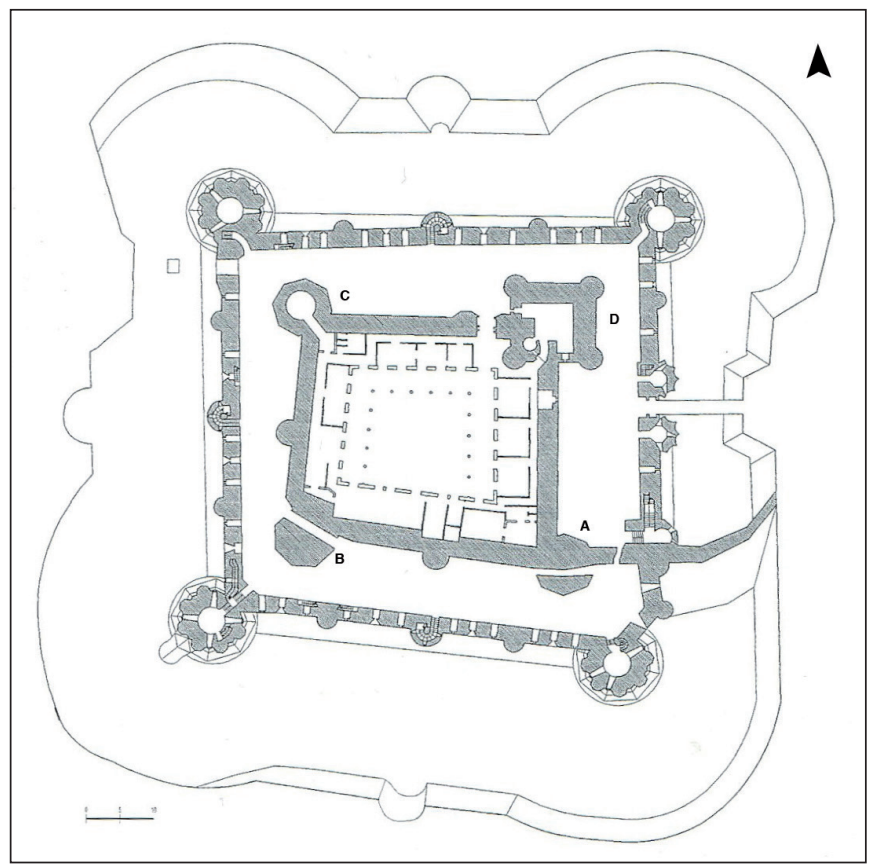

Fig. 1. Planta del Castillo de Coca según Cobos Guerra. A. Torre de Ladrón. B. Torre del Caño. C. Torre de la Prisión. D. Torre del Homenaje.

En 1492, fecha de fácil recuerdo para los testigos, ya comenzaban a asomar los primeros muros del recinto interior, que se elevaban dos tapias ${ }^{16}$. Hasta 1495 las obras prosiguieron a fuerte ritmo. Desde entonces y hasta 1497, tiempo en el que Alonso estuvo a cargo de la mencionada capitanía, las labores languidecieron. Con todo, en torno a 1497, año de la muerte del príncipe don Juan, los habitantes de Coca consideraban completada casi la mitad del edificio ${ }^{17}$. Hacia 1500 la torre del Homenaje se elevaba hasta el inicio de las garitas, se había concluido el recinto exterior con su coronación de pretiles y almenas, y el interior estaba a falta de los remates de muros y torres. También se había comenzado el foso, que estaba en su mayor parte excava$\mathrm{do}^{18}$. Entre 1500 y 1504 prosiguió la obra al mismo ritmo vertiginoso. Entonces se

15 ARChV, Pl. Civiles, Ceballos (F), C. 1124-1, 2a pieza.

16 ARChV, Pl. Civiles, Ceballos (F), C. 1122-1, 2ª pieza, testigo Andrés de Piña.

17 Idem, declaración de Sebastián de Aparicio.

18 Un testigo dice que hacia 1500 “....estaba hecha la mitad de la fortaleza, porque estava hecha la torre del omenaje, e toda la más parte de la barbacana, e todo lo más de la cava a la rredonda. E vía este dicho testigo quel dicho señor Alonso de Fonseca venía a la dicha fortaleza dende las cassa de palaçio, e andava allí mirando la jente que andava en la obra e hedificios de la dicha fortaleza". ARChV, Pl. Civiles, Ceballos (F), C. 1122-1, $2^{\mathrm{a}}$ pieza, testimonio de Juan García. 
chapó la cava por los lados este, norte y parcialmente por el oeste y el sur; se iniciaron las garitas de la torre del homenaje, que no se terminaron por la caída y muerte del oficial morisco llamado Franco que las aparejaba ${ }^{19}$; y se edificó un cuarto en el lado sur del patio de armas, donde comenzó a habitar el alcaide. Este cuarto, situado frente a la puerta de entrada al patio de armas, subía tres alturas, con una bodega y caballeriza, donde guardaban las cubas del vino; un piso de entresuelos; y una sala principal encima con su cuadra y camarilla, que se abrían al patio y al exterior por medio de ventanas cerradas con rejas de hierro.

En 1504 se abandonaron casi completamente los trabajos ${ }^{20}$. El desposorio de María de Fonseca, hija mayor de Alonso y de María de Toledo, con el marqués del Zenete provocó, como es sabido, una auténtica conmoción en la casa de Coca y Alaejos y en la Corte. Celebrado en secreto en el palacio de Coca al finalizar el día de San Pedro de 1502 y consumado durante esa madrugada, Alonso de Fonseca sólo tomó conciencia de la traición de su hija y esposa en la Pascua de Resurrección de 1504. Esta unión invalidaba el acuerdo impulsado por los Reyes Católicos entre Alonso y su hermano Antonio para que éste heredase el mayorazgo fundado por el arzobispo de Sevilla, a condición de que María casase con su primo Pedro Ruiz de Fonseca, hijo de Antonio. Dispuesto a reconducir la situación, Alonso, aconsejado por sus hermanos Antonio y Juan Rodríguez de Fonseca, obispo de Córdoba, se retiró a Alaejos, donde recluyó a las dos mujeres y forzó la boda entre los primos. Ni los malos tratos infringidos por Alonso, ni la intervención de la reina, que encarceló al marqués y llamó a Medina a María de Fonseca, pudieron doblegar la voluntad de la joven ${ }^{21}$.

El 17 de agosto de 1505 moría Alonso de Fonseca ${ }^{22}$ asistido por su hermano Juan. Lo hacía después de testar y desheredar a su hija desobediente ${ }^{23}$. La fortaleza de Coca, a la que había dedicado buena parte de su fortuna, quedaba inconclusa a la espera de las reformas y novedades que inmediatamente aplicaría su hermano Antonio. Con todo, el resultado de lo realizado era magnífico, una obra maestra de la fortificación, producto de la genialidad de unos arquitectos musulmanes y de la altura de miras de un promotor que pretendió con ello ganar honra y estimación para sí y para su casa.

\section{La fortaleza de Maestre Farax y Alí Caro}

La actividad militar de Alonso de Fonseca, que actuó primero como capitán de su tío el arzobispo, haciendo frente en 1473 al cerco de La Mota puesto por los vecinos de

19 ARChV, Pl. Civiles, Ceballos (F), C. 1124-1, 2a pieza, Alonso de Navasdoro.

20 De hecho, en julio de 1505 el rey ordenaba a los vecinos de Olmedo que permitiesen a Alonso de Fonseca sacar piedra para hacer cal, pues la obra de la fortaleza estaba interrumpida. E. COOPER, ob. cit., p. 183.

21 J. CATALINA GARCÍA, "El segundo matrimonio del primer marqués del Cenete", Estudios de erudición española. Homenaje a Menéndez y Pelayo, Madrid, 1899, pp. 665-681 y F. LAYNA SERRANO, Castillos de Guadalajara, Madrid, 1933, pp. 183 y ss.

22 E. COOPER, Ob. cit., p. 179.

23 Una transcripción del mismo, en F.A. RODRÍGUEZ MARTÍNEZ, Los Fonseca y sus mausoleos en la villa de Coca, Lisboa, 1987, pp. 41-3. 
Medina del Campo y el alcaide de Castronuño - quienes emplearon la artillería contra la torre del homenaje, tal y como demuestran los daños visibles aún hoy en la atalaya $^{24}-$, y después de los Reyes Católicos en los asedios de Toro y Castronuño ${ }^{25}$, hubo de brindarle conocimientos de poliorcética de enorme utilidad para la planificación de su fortaleza. A dichas campañas hay que sumar su participación en la guerra de Granada, donde se generalizó el uso de la artillería, convertida en el arma decisiva para la conquista de algunas plazas consideradas tradicionalmente como inexpugnables ${ }^{26}$. Todo ello tuvo que resultar determinante para adoptar la decisión de construir una fortaleza en Coca, idónea para resistir un ataque artillero, para el que la antigua cerca de la villa estaba totalmente incapacitada.

Junto a ello, su cercanía a la Corte le familiarizó con las últimas actuaciones de los reyes en algunas de sus fortalezas del centro del reino, principalmente en La Mota y Ávila, así como necesariamente con alguno de los arquitectos e ingenieros que trabajaban a su servicio. La intervención de los Reyes Católicos en la barrera y cava de La Mota de Medina del Campo, ejecutada entre 1477 y 1483 después de las experiencias acumuladas durante las campañas contra el ejército portugués, se considera la primera donde se introdujeron cámaras de tiro o galerías de pie de escarpa, es decir por debajo del nivel del terreno, lo que las protegía del ataque enemigo y permitían barrer con escopetería la contraescarpa y el fondo del foso. Igualmente la enorme profundidad de la cava -12 metros- no sólamente pretendía dificultar el asalto sino también el empleo de las minas ${ }^{27}$. La experiencia de Medina se trasladó inmediatamente a otras fortalezas reales cercanas como Ávila, donde en 1483 y 1484 se libraron importantes cantidades de dinero para levantar la barrera de su alcázar ${ }^{28}$, que indudablemente no alcanzó el desarrollo de su precedente. No se conocen los autores de esta última intervención, ni si la barrera se levantó con piedra o ladrillo, pero sí los que intervinieron en la villa de las Ferias: dos mudéjares llamados Maestre Abdalá y el "ingeniero" Alí de Lerma, de los que no han llegado más noticias hasta nosotros ${ }^{29}$.

Tampoco podían resultarle ajenas a Alonso de Fonseca una serie de fortalezas de ladrillo y tapias realizadas recientemente por la nobleza en ambas mesetas. Un grupo muy principal se localizaba en la actual provincia de Ávila y territorios limítrofes,

24 F. COBOS GUERRA, "Los procesos constructivos del castillo de la Mota entre los siglos XII y XV", en B. ARÍZAGA BOLUMBURU y J.Á. SOLÓRZANO TELECHEA (eds.), Construir en la Edad Media, Logroño, 2010, p. 235.

25 Crónica incompleta de los Reyes Católicos, Madrid, 1934, pp. 310-20.

26 Sobre el empleo de la artillería en la guerra de Granada, D.W. LOMAX, "Novedad y tradición en la guerra de Granada, 1482-1491", en M.Á. LADERO QUESADA (edt.), La incorporación de Granada a la corona de Castilla. Actas del Symposium conmemorativo del quinto centenario, Granada 1993, pp. 244-8. Sobre la presencia de Alonso de Fonseca en la guerra en 1487 y 1489, Miguel Ángel LADERO QUESADA, Castilla y la conquista del Reino de Granada, Valladolid, 1967, pp. 251 y 269.

27 F. COBOS GUERRA, "Los procesos constructivos del castillo de La Mota...", pp. 235-244.

28 R. DOMÍNGUEZ CASAS, Arte y etiqueta de los Reyes Católicos. Artistas, residencias, jardines y bosques, Madrid, 1993, p. 319.

29 E. GARCÍA CHICO, Catálogo Monumental de la provincia de Valladolid. Medina del Campo, Valladolid, 1961, p. 18. 
donde se cuentan las de Narros de Saldueña, Torralva (propiedad de María de Toledo, esposa de Alonso de Fonseca), Castronuevo y Foncastín ${ }^{30}$.

Del mismo modo, en sintonía con la inclinación de las clases poderosas hacia las expresiones mudéjares durante la última Edad Media hispana, Alonso de Fonseca apostará por alarifes musulmanes para sus promociones arquitectónicas, a quienes además estimulará a la hora de aplicar sus modismos técnicos y decorativos. En este sentido, conocemos la fascinación que le produjo la arquitectura nazarita pues, coincidiendo con su participación en la guerra de Granada, mandó traer desde aquel reino algunos elementos de carpintería para incluir en los artesonados que había ordenado montar hacia 1485 en su fortaleza de Alaejos :

“...este testigo vido que se traxeron unas piñas ricas labradas de oro, las quales se pusieron en una pieça que está cabe la sala rrica; y al tiempo que las traxeron este testigo diz que oyó desir públicamente que se avían traydo del rreyno de Granada..." ${ }^{31}$.

En el útimo cuarto del siglo XV una de las morerías más importante de Castilla era la abulense ${ }^{32}$. Entre su población, que se calcula en torno a 125 vecinos en 1483 y 160 en $1503^{33}$, un número muy destacado se dedicaba a la construcción. Serafín de Tapia ha dado a conocer los nombres de 14 carpinteros, 10 alarifes y 14 tejeros musulmanes en Ávila en el siglo XV, y ha documentado o recordado su participación en obras concretas de arquitectura doméstica, religiosa y militar de la ciudad y de algunas poblaciones aledañas ${ }^{34}$. Ellos serían los responsables de las construcciones en tierra, madera, ladrillo y yeso del interior de muchos edificios domésticos y religiosos que conviven con fachadas y patios de sillería realizados en tantas ocasiones por canteros trasmeranos. Igualmente, habría que adjudicarles algunas de las renovaciones de la arquitectura religiosa rural que se produjeron en el obispado abulense durante el siglo $\mathrm{XV}$ en cabeceras y torres de iglesias, pero también de algunas de las muestras más relevantes de arquitectura militar en ladrillo, extendidas a ambos lados de la Cordillera Central. Por último, sabemos que fueron requeridos por los reyes, como se trasluce de los adornos mudéjares conservados en el palacio de Santo Tomás de Ávila ${ }^{35}$, y de

30 E. COOPER, Castillos señoriales..., vol. I. 2, p. 369-372.

31 ARChV, Pl. Civiles, Ceballos (F), C. 1123-1, 2a pieza, Bernardo Monje. Sobre la arquitectura nazarí como fuente de inspiración de los arquitectos y promotores castellanos en la segunda mitad del XV, J.C. RUIZ SOUZA, "Castilla y la libertad de las artes en el siglo XV. La aceptación de la herencia de Al-Andalus: de la realidad material a los fundamentos teóricos", Anales de Historia del Arte, 22, no. esp. I, (2012), pp. 155 y ss.

32 M.Á. LADERO QUESADA, Los mudéjares de Castilla en tiempo de Isabel I, Burgos, 1968, p. 17. Ver también G. VIÑUALES FERREIRO, "El repartimiento del 'servicio y medio servicio' de los mudéjares de Castilla en el último cuarto del siglo XV”, Al-Qantara, XXIV, 1 (2003), pp. 179-202.

33 S. de TAPIA SÁNCHEZ, La comunidad morisca de Ávila, Salamanca, 1991, p. 144.

34 S. de TAPIA SÁNCHEZ, "Personalidad étnica y trabajo artístico. Los mudéjares abulenses y su relación con las actividades de la construcción en el siglo XV", en P. NAVASCUÉS PALACIO y J.L. GUTIÉRREZ ROBLEDO (eds.), Medievalismo y Neomedievalismo en la Arquitectura española. Aspectos generales, Ávila, 1990 , pp. $245-252$.

35 J.L. GUTIÉRREZ ROBLEDO, Sobre el mudéjar en la provincia de Ávila, Papeles de arquitectura española 4, Ávila, 2001, pp. 79-82 y M.I. LÓPEZ FERNÁNDEZ, La arquitectura mudéjar en Ávila, Ávila, 2004, pp. 269-271. 
la concesión de una hidalguía de privilegio en 1502 a favor del alarife abulense Alí Caro, bautizado ya como Alonso de Fonseca, por los muchos servicios prestados ${ }^{36}$.

Precisamente Alí Caro ha sido documentado por Cooper como el maestro de la fortaleza de $\mathrm{Coca}^{37}$. Pero, en realidad, aunque deba adjudicársele la maestría de la obra en torno a 1500 , no parece haberle correspondido la planificación de la misma ni la dirección de los trabajos durante los primeros años. La excelencia pretendida por Alonso de Fonseca le llevaría a buscar entre los oficiales más experimentados o entre los criados de los reyes el personaje más adecuado. El nombre de dicho arquitecto sale a relucir en la declaración de un testigo ocular que, siendo niño, acudió a la ceremonia de colocación de la primera piedra del castillo de Coca:

“...el dicho señor Alonso de Fonseca començó a hazer e hedificar la dicha fortaleza de Coca ... desde el primero çimiento della..., porque este dicho testigo la vio començar a edificar, e conosçió el maestro que la començó a haser, que hera un moro que se llamava Maestre Farax, al qual el dicho señor Alonso de Fonseca le dio e vestyó un capuz de grana colorado luego en poniendo la primera piedra de la dicha fortaleza..." ${ }^{\prime 38}$.

El nombre de Maestre Farax aparece en dos contextos distintos en las nóminas de los Reyes Católicos. El mejor documentado es Farax de Gali, maestro mayor de la Alfajería de Zaragoza y de las obras reales de Aragón, miembro de una destacada familia de alarifes mudéjares aragoneses ${ }^{39}$. El otro es Maestre Farax, maestro mayor de los alcázares de Toledo, que en 1482, tras la muerte de Maestre Lope, recibió el cargo de "alcalde mayor y repatidor de las aljamas de los moros del reino" ${ }^{40}$. Este Maestre Farax se ha identificado con Farax Alzadafe, nombrado alcalde mayor de las aljamas en 1446, de quien hay constancia documental desde 1435, cuando aparece citado en Toledo como "Maestre Farax Alçadafi, moro, gesero, albanní" ${ }^{41}$. Sin embargo el excesivo lapso temporal entre una noticia y otra y la existencia de otros alcaldes mayores entre ambas fechas, desaconsejan admitir la coincidencia entre am-

36 S. de TAPIA SÁNCHEZ, "Alí Caro, alarife", en G. del SER QUIJANO, Historia de Ávila. Edad Media (siglos XI-XV), IV, $2^{a}$ parte, Ávila, 2009, pp. 731-736. También, A. ECHEVERRÍA ARSUAGA, "Los CaroAfageme" de Ávila, una familia de alfaquíes y comerciantes mudéjares", en A. ECHEVERRÍA ARSUAGA, Biografias mudéjares o la experiencia de ser minoría: biografias islámicas en la España cristiana, Madrid, 2008, p. 224. Sobre la adopción del nombre de su patrón o protector por parte de los mudéjares conversos, M.A. LADERO QUESADA, Los mudéjares de Castilla y otros estudios de Historia medieval andaluza, Granada, 1989, pp. 73-4.

37 E. COOPER, ob. cit., vol. I.1, p. 183.

38 ARChV, Pl. Civiles, Ceballos (F), C. 1122-1, 2a pieza, declaración en 1535 de Pedro de Nieva, vecino de Coca, de 58 años de edad.

39 A. DE LA TORRE Y DEL CERRO, "Moros zaragozanos en obras de la Aljafería y de la Alhambra", Anuario del Cuerpo Facultativo de Archiveros, Bibliotecarios y Arqueólogos, III (1935), pp. 249-255 y R. DOMÍNGUEZ CASAS, ob. cit., p. 73.

40 R. DOMÍNGUEZ CASAS, ob. cit., p. 65. Sobre el Álcázar antes de las reformas renacentistas, J. CARROBLES SANTOS, "Los orígenes de la fortaleza medieval", en El Alcázar de Toledo: Palacio y Biblioteca. Un proyecto cultural para el siglo XXI, Toledo, 1998, pp. 23-32.

41 A. ECHEVERRÍA ARSUAGA, "De cadí a alcalde mayor. La élite judicial mudéjar en el siglo XV", Al-Qantara, XXIV, 1 (2003), p. 150 (pp. 139-168). 
bos personajes ${ }^{42}$. Tampoco puede identificarse a este Maestre Farax con otros alcaldes mayores toledanos de la época como Abraham Xarafí o Farax de Beidici, pues ambos vivían en $1490^{43}$, cuando sabemos que el maestro del Alcázar había fallecido en $1489^{44}$. Además, el hecho de que a éste se le califique en 1482 como "morador en Toledo" parece indicar una vecindad distinta a la toledana, que sin embargo pudo adoptar más tarde ${ }^{45}$.

Junto a estos Farax, criados de los reyes, existieron en Ávila varios personajes con el mismo tratamiento y nombre a finales del siglo $\mathrm{XV}$, algunos de cuyos parientes presentan coincidencias con los nombres de los alarifes documentados en Coca y Casarrubios en 1500 como Alí Caro, Yuçafe o Açeyte ${ }^{46}$. La inclinación de Alonso de Fonseca por los alarifes mudéjares abulenses está documentada en la fortaleza de Alaejos, donde participaron albañiles de esa vecindad años antes de iniciarse los trabajos en $\mathrm{Coca}^{47}$. Como se ha comentado, dicha preferencia continuó en Coca, donde todos los testigos declararon que los maestros mudéjares provenían de Ávila.

En este sentido, algunas de las formas decorativas de la fortaleza de Alonso de Fonseca aparecen en edificios abulenses coetáneos, lo que parece responder más a la labor de un taller o talleres en los que se ejecutan unos usos y maneras asimilados y practicados a lo largo del tiempo, que a la emulación de una obra maestra proyectada por un maestro ajeno a esa práctica edilicia.

Las fórmulas de Coca y la imaginación del arquitecto responsable del obrador que nos ocupa se evidencian sobre todo en la fortaleza de Casarrubios del Monte (Toledo), que Cooper documentó como obra del mismo taller ${ }^{48}$; pero también en edificios religiosos de La Moraña ${ }^{49}$. Los contrafuertes de la arruinada capilla mayor de la iglesia de Castronuevo remiten inmeditamante a las garitas poligonales de Coca. La espadaña escalonada de dicha iglesia, hermana con la de Pascualgrande, que ha conservado en el ángulo noroeste una pequeña escaraguaita circular desmochada. Esta última iglesia mantiene dos portadas mudéjares rematadas con alfices de vueltas redondeadas ${ }^{50}$, como en Casarrubios y en Coca; una de las cuales, la de vano polilobulado de ladrillo, que imita los arcos de grandes bolsores de cantería de las portadas tardogóticas, culmina con cintas enlazadas que recuerdan los adornos de las caras internas de las almenas de Coca. Igualmente, la torre de la iglesia de Moraleja de Matacabras es buena muestra de la imaginación de ese taller o talleres mencionados, pues las ventanas de las campanas se adornan con baquetoncillos de ladrillo abocelado, que se prolongan sobre el arco de medio punto articulando sendos círculos para

42 En 1454 desaparece de la escena Farax Alzadafe, que es sustituido en el cargo por Maestre Lope, maestro mayor del Alcázar de Madrid e hijo de Maestre Yuça. Mahomad de Toledo, hijo de Farax Alzadafe, siguio vinculado a la corte, pues trabajó como ingeniero para Enrique IV. Idem, p. 152.

43 Idem, p. 166.

44 R. DOMÍNGUEZ CASAS, ob. cit., p. 183.

45 Farax aparece citado en 1482 como "morador" y en 1489 cuando se certifica su defunción y se nombra su sustituto, como "vecino". Idem, p. 177, n. 211, y p. 212.

46 S. de TAPIA SÁNCHEZ, La comunidad morisca ..., pp. 425 y ss.

47 ARChV, Pl. Civiles, Ceballos (F), C. 1123-1, $1^{\text {a }}$ pieza.

48 E. COOPER, ob. cit., vol I, 1, pp. 183 y ss.

49 Idem, p. 52.

50 M.I. LÓPEZ FERNÁNDEZ, ob. cit., p. 219. 
adorno de las enjutas; el intradós de los dichos vanos se achaflana y se adorna de trecho en trecho con ladrillos de medio bocel, en imitación de los adornos de bolas de la cantería ${ }^{51}$; y, por último, este cuerpo de ventanas se remata con una cornisa de ladrillos aplantillados de doble bocel y nacela intermedia que da paso a una terraza cercada con almenas y adornada en sus esquinas con garitas circulares, donde se repite un peculiar sistema decorativo presente en los merlones de la barrera de Coca: una superficie ondulada obtenida a partir de la sucesión de líneas verticales de ladrillos curvos.

En definitiva, todo parece indicar que la fortaleza de Coca es obra de un taller abulense dirigido en los años 80 por un maestro denominado Farax, que sería sustituido a finales de siglo por Alí Caro. Indudablemente, y dada la perfección de la fortaleza, no era la primera vez que este obrador realizaba una obra de carácter militar. Lamentablemente, la desaparición de la barrera del alcázar de Ávila, del castillo de Foncastín y la casi total del de Torralva impide poder relacionarlos con Coca. Sin embargo, la adecuación en la villa del Eresma de las nuevas barreras nacidas en Medina del Campo, con profundos fosos y multitud de bocas de tiro en la escarpa, así como el uso de numerosas medidas contraminas, incluida la utilización de un saliente a pie de foso, a modo de caponera, para proteger un pozo contramina ${ }^{52}$-que recogía las aguas de una fuente natural cercana llamada el Caño o el Cañuelo ${ }^{53}$-, precisaron de un proyectista conocedor de las últimas novedades ${ }^{54}$.

Ese taller participó también en la fortaleza de Casarrubios del Monte, promoción de Gonzalo Chacón, comenzada en 1496. Alí Caro regentaba entonces el taller familiar, en el que partipaban otros dos hermanos suyos: uno llamado Aceyte y otro nombrado posiblemente Yusafe. Caro recibía en Casarrubios una quitación anual por la maestría de 8.000 maravedís, además de un sueldo de 2 reales cada día que permanecía en la obra, pues como tal maestro se ausentaba con frecuencia para atender otras empresas ${ }^{55}$.

Entre ellas se encontraba la fortaleza de Coca, cuyo conocimiento por parte de Chacón, tuvo que resultar definitivo para la elección del maestro abulense. En los citados libros de cuentas conservados de la obra de $\mathrm{Coca}^{56}$, aparece esporádicamente

51 Idem, pp. 203-4.

52 F. COBOS GUERRA, "La fortificación española del primero Renacimiento: entre la arqueología de la arquitectura y la arquitectura de papel”, Congreso internacional Ciudades Amuralladas, Navarra, 2007, p. 291.

53 La fuente se encuentra en la ladera del Eresma, cercana al ángulo suroeste de la fortaleza. Véase, J.F. BLANCO GARCÍA, "Fortificación y organización...”, pp. 242 y 252.

54 Se ha intentado vincular las novedades de La Mota con algún ingeniero o artillero cristiano, como Maestre Fernando, artillero que se sabe "trabajava en dar horden en el faser de la cava". Con quien no es posible relacionarlas es con el aragonés Ramiro López, quien había sido llamado en 1482 para participar en la guerra de Granada, y que con el tiempo se convertiría en el ingeniero de Salsas. F. COBOS GUERRA, "Etapas constructivas...", pp. 280-1. Sobre éste último personaje, F. COBOS GUERRA y J.J. de CASTRO FERNÁNDEZ, “Artillería y poliorcética castellana en la estrategia de Fernando el Católico contra Francia (documentos para su estudio)", Glaudius, XX (2000), pp. 251-268.

55 E. COOPER, ob. cit., vol. I, 1, pp. 183 y 186-7.

56 Juan de Fonseca los entregó a la justicia después de que su prima Mayor de Fonseca le acusara a él y a su padre Antonio de haberlos destruido para impedir el conocimiento exacto de lo gastado por Alonso de Fonseca y María de Toledo en la fortaleza. ARChV, Pl. Civiles, Ceballos (F), C. 1125-1, dos últimas piezas. 
Alí Caro, que cuando lo hace cobra 50 maravedís, a los que habría que sumar la quitación anual por la maestría ${ }^{57}$. Junto a él se reseña un importante plantel de trabajadores musulmanes regido por un oficial llamado Mahoma, que cobra 62 maravedís diarios y que debía de actuar como capataz de la cuadrilla. Ésta estaba compuesta por Maestre Patón, Hamed Rincón, Yuçafe de los Toros, Prado, un hermano de éste, Brayme, Alí de Segovia, Madrid, Mahoma Saydón, Álvar Ruiz y Calí. Todos ellos cobraban lo mismo, 50 maravedís por una jornada completa, descontándoseles los retrasos o las medias jornadas proporcionalmente. Todavía se puede señalar un nombre más pues, como ya se ha indicado, hacia 1504 un morisco llamado Franco murió al caer desde la torre del Homenaje cuando estaba comenzando los caracoles.

La presencia de estos albañiles en Coca era bastante constante. Durante largas temporadas participaban 11 ó 12 de ellos al tiempo, aunque la existencia de otras obras a cargo de ese taller motivaba largas ausencias, reduciéndose su presencia a la mitad. Sea como fuere, lo cierto es que sobre ese taller de alarifes musulmanes parece haberse sustentado la mayor parte de la obra. Así se constata en la primavera de 1500, y no hay porqué dudar de que así fuera el resto del tiempo. De hecho, en los pliegos de las cuentas se reseñan muy pocos oficiales cristianos; concretamente un Gómez, carpintero, y un Francisco Vallejo, albañil, que cobraraban 40 maravedís diarios cada uno.

La asistencia de este Francisco Vallejo, vecino de Coca, está corroborada por su hijo Antonio Vallejo, maestro de obras y testigo en el pleito que enfrentó a Mayor de Fonseca con Juan de Fonseca. Éste declara la soldada que recibía su padre, aunque se "equivoca" al hacer la comparación con lo recibido por los oficiales musulmanes:

"Que oyó dezir a su padre, que se dezía Francisco Vallejo, que hera maestro de albañería, que en el tiempo que Alonso de Fonseca labraba la dicha fortaleza de Coca avía labrado en ella como maestro, e comúnmente le davan de salario cada un día quarenta maravedís, e que les dezía que hera lo que más ganava un maestro del dicho ofiçio, e que a otros ofiçiales e maestros les davan a rreal (de a 31 maravedís) cada día y no más" 58 .

En realidad, como hemos visto, los oficiales de Alí Caro cobraban 10 maravedís más que los cristianos $^{59}$, lo que abunda en el destacado papel jugado por esa cuadrilla de alarifes abulenses y, sobre todo, en la inexistencia de discriminación profesional por razones religiosas o culturales, circunstancia esta última que coincide con lo que

57 En 1505, cuando murió Alonso de Fonseca, su hija Mayor de Fonseca pagó “mill y quinientos maravedís ... a Alonso de Fonseca, maestro de las hobras, de los terçios primero y segundo del salario que tenía de Alonso de Fonseca, su padre". Como ya se ha dicho, este maestro, bautizado como Alonso de Fonseca, no es otro que Alí Caro, quien cobraría tan exigua cantidad en Coca (muy lejos de los 8.000 mrs. pagados en Casarrubios) por el estancamiento de los trabajos. ARChV, Reales ejecutorias, C. 917-2

58 ARChV, Pl. Civiles, Ceballos (F), C. 1124-1, 2a pieza.

59 “...que al dicho tiempo en la pregunta contenido vio que labravan en ella unos moros de Ávila, e dezían que llevaban a rreal e medio (de a 31 maravedís) cada día de jornal”. ARChV, Pl. Civiles, Ceballos (F), C. 1124-1, 2a pieza, Diego de Rujas. 
se ha podido documentar en el reino de Aragón, donde el análisis de algún libro de cuentas proporciona semejantes resultados ${ }^{60}$.

Fueron estos maestros musulmanes los responsables de la excelencia del castillo de Coca. Original de Maestre Farax es la insistencia en la acumulación de torres y torrecillas en las partes altas de los muros. Las torres poligonales esquineras de ambos recintos se cubren en su mitad superior por garitas también poligonales que desarrollan una multitud de troneras. La apariencia desde el exterior, donde la contraescarpa oculta la mitad inferior del primer recinto y éste, a su vez, la misma parte del interior, es la de un edificio erizado de torres que busca el desistimiento de los asaltantes. Es también un elemento particular de este edificio la multiplicación de los elementos poligonales, que traen a la memoria soluciones de la arquitectura militar almohade ${ }^{61}$. Poligonales son las torres de ambos recintos y sus garitas; y ochavadas, pero de lados cóncavos, las que flanquean la antigua poterna. Sólo la torre del homenaje, el bloque peor resuelto visualmente debido a su corta alzada -sin duda como consecuencia de las limitaciones impuestas por la artillería-, se articula de manera convencional, cuadrada y con cubos y garitas curvas. Muy singulares son las almenas -dispuestas como es habitual sobre arquetes, en este caso asentados sobre dos órdenes de ladrillos aplantillados-, las cuales son muy altas y se construyen por medio de varias líneas verticales de ladrillos curvos, que forman una superficie ondulada de clara vocación ornamental, que funciona como crestería de los distintos recintos y torres, intensificando la acumulación visual de elementos en la partes altas de los paños (Fig. 2).

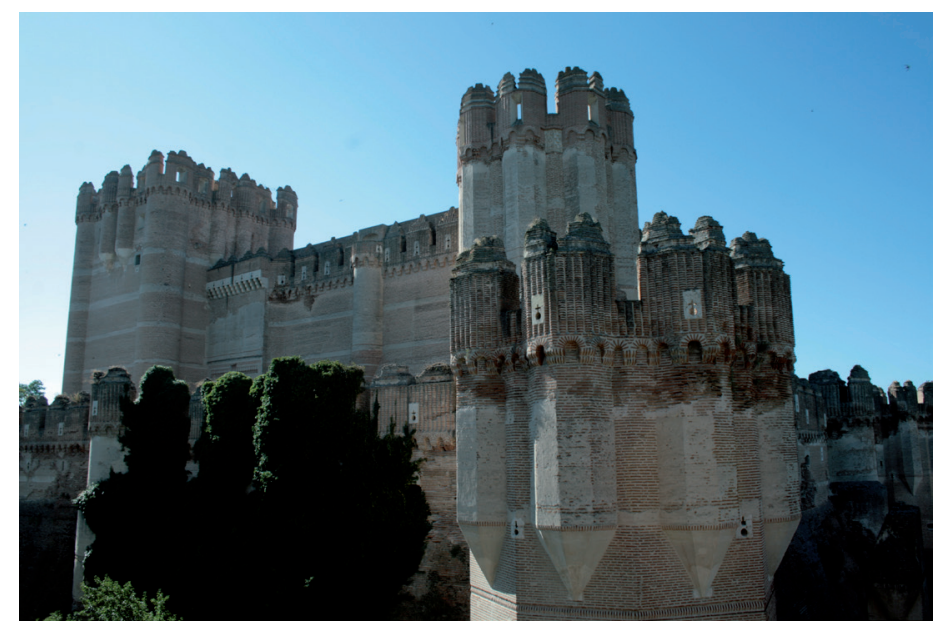

Fig. 2. El Castillo de Coca desde el Noroeste.

60 G. M. BORRÁS GUALIS, "El artesano mudéjar en Aragón”, L’Artista-Artesá Medieval a la Corona d'Aragó, Lleida, 1999, pp. 70-2 y "Sobre la condición social de los maestros de obras moros aragoneses", Homenaje al profesor Julián Gállego. Anales de Historia del Arte, 2008, Volumen Extraodinario 1, p. 100. Una visión globalizadora, con atención sobre el fenómeno de la esclavitud, R. GÓMEZ, Los constructores de la España Medieval, Sevilla, 2009, pp. 87 y ss.

61 S. MARQUEZ BUENO y P. GURRIARÁN DAZA, "Recursos formales y constructivos en la arquitectura militar almohade de al-Andalus", Arqueología de la arquitectura, 5, 2008, pp. 121-123. 
$\mathrm{Al}$ interior se despliega todo un catálogo de soluciones constructivas para las cubiertas, en las que se empleó en exclusividad el ladrillo. Como recordó Pita Andrade, los pasadizos y salas de todo el castillo se cubren con "bóvedas de medio y cuarto cañón, de medio cañón apuntadas, de arista, de media naranja, baídas y de rincón de claustro, esquifadas, de nervios..." con las que no sólo se da respuesta a encuentros y espacios irregulares, sino que se insiste en la variedad y la imaginacion que caracterizan toda la obra ${ }^{62}$.

Por si esto no fuera suficiente, Alonso de Fonseca mandó aplicar una viva policromía a las partes más destacadas. Los encargados de dicha decoración fueron también mudéjares, como evidencian las características de dicha pintura: limitada paleta de colores (rojo almagre, blanco del revoco y negro de humo); empleo de colores planos sin sombras ni modelado; diseño fundamentalmente geométrico, con algunos motivos florales y animados de dibujo sumario y bordes perfectamente definidos; e insistencia en la repetición de los motivos, que se agrupan en paños enmarcados por cintas de líneas entrelazadas, que compartimentan y en último extremo desvirtúan la planitud del muro ${ }^{63}$.

Al exterior, a pesar de las pérdidas sufridas por efecto de los agentes atmosféricos, todavía se reconocen una serie de cintas enfoscadas que ciñen los muros de ambos recintos, sobre las que se pintaron motivos geométricos, heráldicos y epigráficos. Variadas figuras geométricas se aplicaron en rojo sobre el enlucido que cubría las garitas ochavadas y semicirculares de todo el conjunto, donde todavía se aprecian en algunos casos las líneas grabadas sobre el mortero fresco que servían de guía. Las bases de las garitas se decoraron imitando fábricas de ladrillos dispuestos a espiga, mientras alguna de las escaraguaitas curvas adornaron las llagas con cintas blancas policromadas de rojo en su parte central. Bajo los arquetes de los matacanes ciegos se distinguen algunas rosetas, que volverán a emplearse en la Sala de los Jarros del interior de la fortaleza.

$\mathrm{Al}$ interior, las pinturas no se limitan a las bóvedas y muros de las estancias de las torres del recinto interior, incluida la del Homenaje, sino que asombrosamente se desarrollan incluso por las casamatas y troneras del recinto exterior, que sólo iban a ser contempladas por los artilleros y escopeteros (fig. 3). Aparejos de sillería y de ladrillo simulados en los muros se combinan con bóvedas pintadas donde se imitan formas estrelladas y plementos de cantería. La misma arquitectura fingida se despliega en algunas puertas de acceso a las salas y casamatas, adornadas con sillares y ladrillos pintados que recuerdan soluciones presentes en el palacio de los Reyes Católicos de Santo Tomás de Ávila o en algunas iglesias de Cuéllar ${ }^{64}$. En otras ocasiones los muros se cubren con formas geométricas y lacerías, que permiten imaginar el aspecto que tuvieron originalmente las decoraciones exteriores. En algunas salas proliferan los elementos vegetales, como en la denominada de los Jarros, donde este motivo

62 J.M. PITA ANDRADE, art. cit., p. 213.

63 C. RALLO GRUSS, "El castillo de Coca y su ornamentación”, Anales de Historia del Arte, 6 (1991), pp. 13-34 y Aportaciones a la técnica y estilística de la pintura mural en Castilla a final de la Edad Media, Madrid, 1999, t. I, pp. 69 y ss.

64 M.I. LÓPEZ FERNÁNDEZ, ob. cit., pp. 270-1 y C. Rallo Gruss, Aportaciones ..., p. 88. 
se combina con rosetas, tallos vegetales y flores enmarcadas por arcos peraltados entrelazados.

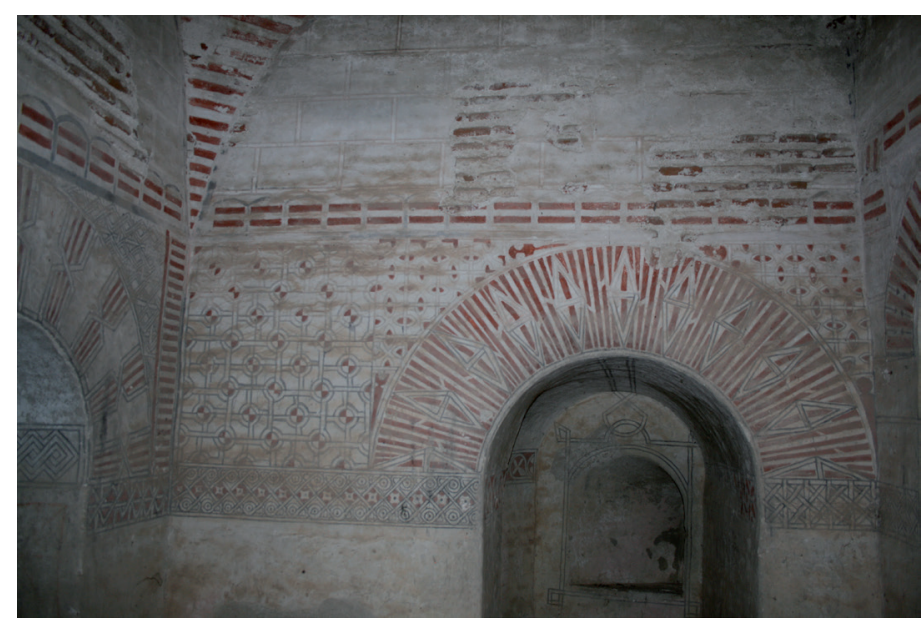

Fig. 3. Castillo de Coca. Casamata del recinto interior.

\section{La renovación palaciega de Antonio de Fonseca, obra de Diego Rodríguez y Juan de Ruesga}

A la muerte de Alonso de Fonseca en agosto de 1505 aún no se había solucionado la crisis provocada por su primogénita al casarse en secreto con el marqués del Zenete. La estrategia seguida por la Reina Católica, radicalmente opuesta a dicho matrimonio, motivó, como se ha apuntado antes, la prisión de Rodrigo de Mendoza y el intento de convencer personalmente a María de Fonseca, que fue recluida en una de las torres del palacio real de Medina del Campo, desde donde era llamada insistentemente por la reina para que confesase no haberse desposado con el marqués y poder validar el posterior matrimonio forzado con su primo Diego Ruiz. La presión ejercida contra ellos comenzó a desmoronarse con la desaparición de la reina. Fernando el Católico tuvo que liberar de su encierro de Simancas al marqués, pero mantuvo la intimidación sobre la joven, que fue enviada a la fortaleza de Zamora, tenencia de los condes de Alba de Aliste, fieles aliados del rey regente, en tanto se dirimía ante el obispo de Segovia el pleito matrimonial que tenía que sentenciar la validez de uno de los enlaces. Esta era la situación a la muerte de Alonso de Fonseca, que se complicó aún más al año siguiente cuando Felipe el Hermoso, enfrentado a los Fonseca a causa de las maniobras del obispo de Palencia a favor de Fernando el Católico ${ }^{65}$, decidió confiar a María a las monjas de las Huelgas de Valladolid, de donde salió para con-

65 La firme posición de Juan Rodríguez de Fonseca y de Antonio de Fonseca a favor de Fernando el Católico provocó su alejamiento de la Corte durante el corto reinado del borgoñón. A. SAGARRA GAMAZO, "La reina Juana y don Juan de Fonseca: ¿Una hoja de servicios con precio político?”, Revista de Estudios 
traer casamiento eclesiástico con el marqués ${ }^{66}$, sin esperar la sentencia de un litigio que éste había conseguido trasladar a Roma.

La prevención de Antonio de Fonseca contra Rodrigo de Mendoza, que se hacía llamar señor de Coca y Alaejos ${ }^{67}$ y se jactaba de que haría otro palacio como el de La Calahorra en $\mathrm{Coca}^{68}$, no se limitaba al temor de que procurase su muerte o, sobre todo, la de su hijo Pedro Ruiz, principal obstáculo para la validación del matrimonio de los marqueses ${ }^{69}$, sino de que intentase la toma por la fuerza de las fortalezas ${ }^{70}$, por lo que Fonseca se apresuró a terminar las defensas de Coca.

La situación del castillo cuando lo recibió Antonio de Fonseca es bien conocida merced a las declaraciones de los testigos del pleito que enfrentó a los hijos de Antonio de Fonseca con Mayor de Fonseca y, sobre todo, a un memorial que presentaron aquellos de lo fabricado por Antonio desde $1505^{71}$. Según este documento, a la muerte de Alonso de Fonseca faltaba por completar la cava en su parte más inexpugnable, es decir la que corría a lo largo del Voltoya y volvía alrededor de la torre del Caño; la torre del Homenaje, paralizada a la altura del inicio de las garitas; y el patio, en el que sólo se había fabricado el cuarto del alcaide, situado al sur.

En principio las obras se centraron en el foso, para lo que se empleó la misma mano de obra de moriscos abulenses ${ }^{72}$. La cava había quedado detenida en vida de Alonso de Fonseca en su lado suroccidental, donde sólo se había levantado una contraescarpa de 2 ó 3 tapias de altura. Sobre ello Antonio completó el muro, que se distingue del resto, como ha señalado Cooper $^{73}$, porque no es alamborado, sino vertical; reflejo, bien de su situación sobre el cauce del Voltoya -que impedía la existencia de un relleno de tierra exterior-, bien de un cambio de planes tras el hundimiento que se

Colombinos, Junio de 2010 (nº 6), pp. 13-23 y J. MARTínEZ MILLÁN (dir.), La corte de Carlos V. Segunda Parte. Los Consejos y los consejeros de Carlos V, vol. III, Madrid, 2000, p. 138.

66 J. CATALINA GARCÍA, art. cit., p. 677.

67 J.M. MARCH, S.J., "El primer marqués del Cenete. Su vida suntuosa", $A E A$, XXIV (1951), p. 55.

68 M. GÓMEZ MORENO, "Sobre el Renacimiento en Castilla. I Hacia Lorenzo Vázquez", Archivo Español de Arte y Arqueología, I (1925), p. 39.

69 Hasta 1507, en que murió Pedro Ruiz de Fonseca en Burgos (ARChV, Pleitos Civiles, Lapuerta (F), C. 1521-8), éste y su padre vivieron protegidos por escuderos armados que los acompañaban de continuo. ARChV, Pl. Civiles. Alonso Rodríguez (D), C. 105-5 y C. 109-1. No es de extrañar la desconfianza hacia el marqués a tenor su fama, M. FALOMIR FAUS y F. MARÍAS, "El primer viaje a Italia del Marqués del Zenete", Anuario del Departamento de Historia y Teoría del Arte, VI (1994), p. 103.

70 En 1505 había gente de armas en Coca porque "se temía el dicho Antonio de Fonseca que el marqués del Çenete viniese a tomar la dicha fortaleza de Coca e de Alaejos por las diferençias que abía entonçes...". ARChV, Pl. Civiles, Ceballos (F), C. 1124-1, $1^{\text {a }}$ pieza, declaración de Antonio de Coca. Los temores no eran infundados, pues parece que existió una intentona, ya que, como relata Fernández de Oviedo, "por parte de los Fonseca faltó poco para quemarle bivo [al marqués del Zenete] en la cava o fosa de la fortaleza de la villa de Coca por yndustrya de un traydor...”. G. FERNÁNDEZ DE OVIEDO, Batallas y Quinquagenas, Edición de J.B. de Avalle-Arce, Salamanca, 1989, p. 396 (f. $862 v^{\circ}$ ).

71 ARChV, Pl. Civiles, Ceballos (F), C. 1122-1 a 1125-1. El memorial está en la Caja 1124-1, 2a pieza. Las obras de Antonio de Fonseca comenzaron en 1505 tal y como declaró Alonso Flores, mayordomo de las mismas (Caja, 1124-1, 2a pieza).

72 Uno de los testigos llamado Alonso Grajo declara que, después de acabadas las obras de la cava que hizo Antonio de Fonseca, "fue con unos moros que lo hizieron e labraron a la çibdad de Ávila, que heran vezinos della". ARChV, Pl. Civiles, Ceballos (F), C. 1124-1, $1^{\text {a }}$ pieza.

73 E. COOPER, ob. cit., vol. III, p. 1274. 
produjo de esa zona en el transcurso de las obras llevadas a cabo por Antonio y que le obligó a reconstruir un buen tramo ${ }^{74}$. Al sur, chapó de ladrillo toda la contraescarpa hasta tocar la cerca medieval que cortaba el foso, la cual se perforó para permitir el recorrido a través de él ${ }^{75}$.

A ese mismo momento debió corresponder la conclusión de la torre del Homenaje, cuya obra se había paralizado en el arranque de las garitas, donde Alonso había mandado pintar una la inscripción, hoy casi ilegible, que hacía referencia a su intervención en la obra. El cambio del aparejo en esa zona es bien visible: desde la altura de los semiconos donde asientan los caracoles se emplearon ladrillos más cortos y gruesos que los inferiores. La torre se remató con una bóveda de arista (la única de todo el recinto), cierre de una dependencia que significativamente no se decoró con pinturas. Sobre la bóveda se fabricó un aljibe y se remató con una terraza, cuyos pretiles y almenas cabalgan -según disposición empleada por Alonso de Fonseca en el recinto exterior-sobre matacanes ciegos formados por arquillos sostenidos por dos ordenes de ladrillos aplantillados. Existe, sin embargo, una diferencia que distingue estos remates de los elaborados en vida de Alonso: los pretiles en vez de decorarse con filas verticales de ladrillos curvos, lo hicieron con ladrillos en esquinilla, solución que volvió a emplearse en el resto de las cresterías de las atalayas y paños del recinto interior ${ }^{76}$.

Al tiempo que se completaban el foso y la torre del Homenaje, Antonio de Fonsea decidió dar un giro radical a la obra del interior de la fortaleza con la intención de convertirla en una residencia palaciega a la moda. Sus prolongadas estancias en Andalucía, en el seno de la Corte; su viaje a Italia en 1495 como embajador de los Reyes Católicos, que le llevó a Milán y Roma ${ }^{77}$; y el conocimiento de la arquitectura nobiliaria andaluza, que en las dos primeras décadas del XVI produjo una feliz simbiosis entre la tradición mudéjar y la incorporación de nuevos materiales importados de Italia, le llevaron a replantear el interior de la fortaleza, que se convirtió en un palacio andaluz con elementos genoveses trasplantado a Castilla.

Los protagonistas de dicho conjunto fueron el propio Antonio de Fonseca, el alarife sevillano Diego Rodríguez y el cantero trasmerano Juan de Ruesga. Así recordaba un testigo la elaboración de las trazas del patio:

“... antes que se començasen a hazer los dichos tres quartos [del patio] vio hazer la traça de ellos a un maestro de Sevilla que se dezía Diego Rodríguez e otro que se dezía Juan de Riesga, que hera maestro de cantería, y ellos juntamente con el dicho Antonio de Fonseca se hizo la traça de los dichos tres quartos e aposentos dellos, y este testigo la vio hecha antes que se començasen..."78.

74 ARChV, Pl. Civiles, Ceballos (F), C. 1124-1, $1^{\text {a }}$ pieza.

75 Ibidem, $2^{\mathrm{a}}$ pieza.

76 ARChV, Pl. Civiles, Ceballos (F), C. 1124-1, $2^{\text {a }}$ pieza, testimonio de Alonso Flores, mayordomo de Antonio de Fonseca en la obra.

77 L. SUÁREZ FERNÁNDEZ, Política internacional de Isabel la Católica. Estudio y documentos, Valladolid, 1969, IV, pp. 71 y ss. Sobre Antonio de Fonseca, J. MARTÍNEZ MILLÁN (dir.), La corte de Carlos V..., pp. 137-140.

78 ARChV, Pl. Civiles, Ceballos (F), C. 1124-1, 2 a pieza, Juan de Olivares. 
Evidentente ese Juan de Riesga no es otro que Juan de Ruesga, arquitecto tardogótico suficientemente conocido, maestro de la catedral de Palencia entre 1506 y 1514 en que muere, y por lo tanto estrechamente vinculado al obispo Juan Rodríguez de Fonseca $^{79}$. Su participación en el edificio, el primero de carácter doméstico que se le ha podido documentar, parece haberse limitado a la colaboración para diseñar las plantas y alzados, pues su nombre no vuelve a ser recordado por los testigos, como tampoco lo fue el de ningún cantero más. Junto a Ruesga y el comitente participó en las trazas el alarife sevillano Diego Rodríguez, quien parece haber sido el verdadero protagonista de la obra ${ }^{80}$. Este albañil era, según los testigos, alarife prestigioso, y fue llamado por Antonio de Fonseca para labrar los cuartos del patio de Coca:

“...vio que labrava uno que llamavan Diego Rodríguez de Sevilla, que hera maestro de alvañería, e le traxo desde Sevilla el dicho Antonio de Fonseca para que labrase en la dicha fortaleza, porque le tenían por muy gran maestro..." ${ }^{81}$.

Aunque lo frecuente del nombre suscita dudas en cuanto a su identidad, puede asimilarse al Diego Rodríguez que trabajó al servicio de don Fadrique Enríquez de Ribera durante las décadas de 1520 y 1530 en la Casa de Pilatos ${ }^{82}$. Una obra suya, escriturada en la tardía fecha de 1538, cuando es citado como Diego Rodríguez el Viejo, y realizada junto a diez oficiales que trabajaron a sus órdenes, la escalera principal de dicho palacio hispalense ${ }^{83}$, es muestra de las soluciones decorativas propuestas por este maestro, que permiten imaginar la ornamentación de Coca.

En efecto, todos los testigos describen la reforma de Antonio de Fonseca en función de la existencia de los elementos de mármol -columnas del patio, ventanas y miradores altos-, los artesonados de las distintas salas, realizados con madera de Valsaín; y las decoraciones de yesos y azulejos. Los azulejos, traídos de Toledo y sobre todo de Sevilla ${ }^{84}$, en buena parte procedentes del taller de Niculoso Pisano ${ }^{85}$,

79 La última aportación sobre él, con toda la bibliografía anterior, en B. ALONSO RUIZ, "El arquitecto Juan de Ruesga", Los últimos arquitectos del Gótico, Madrid, 2010, pp. 219-269.

80 Aunque posiblemente se suscribiera un contrato con un cantero para abrir los cimientos y el algibe, así como para completar los miembros de cantería necesarios, por ejemplo, para sostener la escalera principal, la previsión de introducir mármoles genoveses para los corredores del patio y los miradores, así como para las ventanas, convirtió la obra en una fábrica fundamentalmente de albañilería.

81 ARChV, Pl. Civiles, Ceballos (F), C. 1124-1, $2^{\mathrm{a}}$ pieza, Alonso de Heredia.

82 Está documentado al servicio del marqués de Tarifa entre 1526 y 1538. V. LLEÓ CAÑAL, La Casa de Pilatos, Madrid, 1998, pp. 26-29. Además, existe un Diego Rodríguez de San Román, ollero sevillano asociado profesionalmente a Niculoso Pisano, que no puede coincidir con éste que nos ocupa. A.J. MORALES, Francisco Niculoso Pisano, Diputación Provincial de Sevilla, Sevilla, 1977, pp. 15 y ss.

83 A. SANCHO CORBACHO, La cerámica andaluza. Azulejos sevillanos del siglo XVI, de cuenca. Casa de Pilatos, Laboratorio de Arte, Universidad de Sevilla, Sevilla, 1953, p. 10.

84 "Y los azulejos, que deçían a este testigo que se trayan de Sevilla...". Declaración de Alonso García, tejero que trabajó proveyendo ladrillos para la fortaleza. ARChV, Pl. Civiles, Ceballos (F), C. 1124-1, $1^{\mathrm{a}}$ pieza.

85 O. VILLANUEVA ZUBIZARRETA, Colección de azulejería del castillo de Coca. Estudio y Catalogación, Valladolid, 2001, pp. 54-7. Sobre los azulejos de cuenca de Pisano, A.J. MORALES, ob. cit., pp. 58 y ss. y A. PLEGUEZUELO, "Francisco Niculoso Pisano: datos arqueológicos", Faenza, LXXVIII (1992), 3-4, pp. 178 y ss. Agradezco a la doctora Villanueva su información y aportación bibliográfica sobre los mudéjares abulenses y las series de azulejería de Coca. 
decoraban los arrimaderos de los corredores $^{86}$, la caja de la escalera, los zócalos de las distintas estancias y, sobre todo, la fachada del cuarto levantado por Alonso de Fonseca donde vivía el alcaide (Fig. 4.). Este cuarto, frontero de la puerta por donde se entra al patio, quedó sin galerías y se adornó con ventanas de Génova y una decoración de yesos y azulejos que los testigos encarecen:

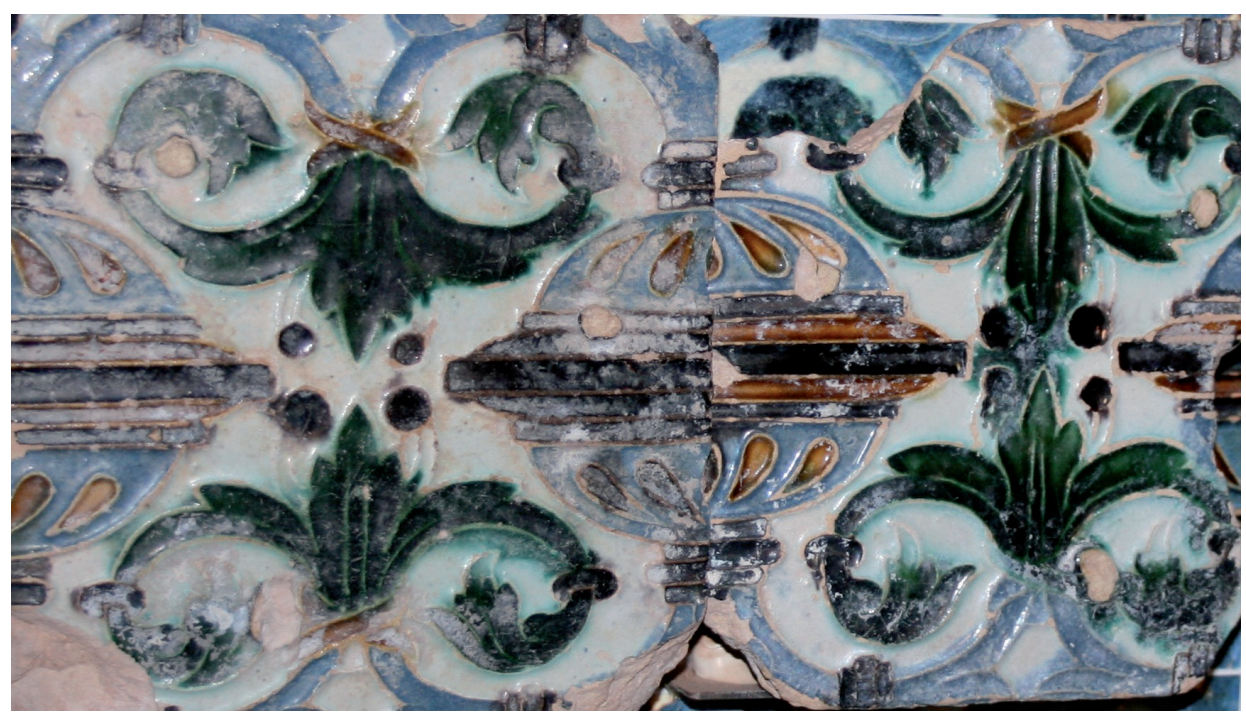

Fig. 4. Castillo de Coca. Azulejos de cuenca.

“...hizo el dicho Antonio de Fonseca chapar de azulejos como agora está la delantera del dicho quarto que sale al patio, e las ventanas que estavan en el dicho quarto hizo hazer de otra manera que solía estar, e puso los mármoles de Génova que están en ella; porque antes que Antonio de Fonseca començase a hazer lo susodicho, el dicho quarto biejo del alcalde estava hecho e labrado de cal y ladrillo... ${ }^{87}$.

Estas dependencias preexistentes condicionaron la forma del patio. Los cuartos nuevos se redujeron a tres, en los que se habilitaron sus corredores de columnas de mármol, quedando el de Alonso de Fonseca cerrado. Afortunadamente se ha conservado una traza del XVI con la disposición de la planta principal del patio, donde se señalan las salas y cámaras, así como la escalera ${ }^{88}$. Ésta, que los testigos describen

86 Uno de los testigos habla de los “...los azulejos questán alrrededor del corredor”. ARChV, P1. Civiles, Ceballos (F), C. 1122-1, 2a pieza, Miguel de Madrigal.

87 ARChV, Pl. Civiles, Ceballos (F), C. 1124-1, 2a pieza, Pero Hernández. Otro testigo, llamado Alonso Flores, describe así dicha fachada: "E hizo más el dicho Antonio de Fonseca toda la delantera del dicho quarto como agora está de azulexos e yesería, e hizo las ventanas nuebas, altas e baxas del dicho quarto, e puso los mármoles de Génoba questán en ellas". ARChV, Pl. Civiles, Ceballos (F), C. 1122-1, 2ª pieza.

88 Fue publicada por J.M. PITA ANDRADE, art. cit., pp. 210 y 216 . Quizás encargada como prueba documental para alguno de los numerosos pleitos que se siguieron durante el XVI a cuenta de las obras de la fortaleza, fue dibujada por un desconocido maestro llamado Simón González, que no utilizó pitipié ni fue muy cuidadoso con las medidas. 
como de piedra, sin que en ningún momento se comente la presencia de mármol en ella ${ }^{89}$, se alojó en una caja única pero no abierta, pues presentaba la particularidad de disponer la boca y la desembocadura en la misma vertical, seguramente con la intención de aprovechar sus muros para la decoración de azulejos, tal y como ocurre en la Casa de Pilatos sevillana. Su cubierta se cerraba con un artesonado con labores de talla y pintura al romano:

“...E que en la dicha sobrescalera queste testigo vio, está hecha de talla e dorado, de çiertos artesones, e çiertas molduras doradas, e çiertos florones dorados, e çiertos alizeres del rromano, e çiertas hojas del rromano questán en los mesmos artesones, e otras pinturas que están entre medias..." ${ }^{90}$.

Desde el descansillo de la escalera principal, partía otra, no dibujada en la planta citada, que subía a los andenes del recinto interior. A su vez, desde la sala contigua a la caja de la escalera se armó otra de dos tramos para acceder a los miradores que corrían sobre los citados andenes.

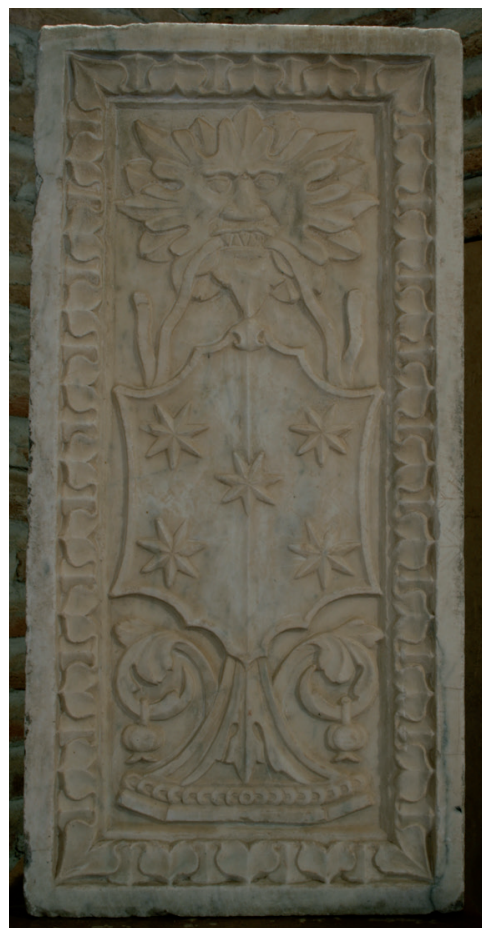

Fig. 5. Castillo de Coca. Detalle de un pedestal o un antepecho. Mármol.

89 En la actualidad se ha realizado una reconstrucción parcial de la escalera aprovechando pedestales de mármol y balaustres, que deben corresponder a los corredores altos del patio o a los antepechos de miradores o ventanas.

90 ARChV, P1. Civiles, Ceballos (F), C. 1123-1, 7ª pieza, declaración de 1543 de Juan de Flandes, pintor, vecino de Salamanca. 
El salón principal, denominado "sala rica", se situaba al este, sobre la poterna que mira a la villa, donde se abría una enorme ventana protegida con una reja. Al norte se dispusieron tres cámaras con sendas ventanas (en la planta sólo se dibujaron dos), y dos cuadras en los extremos; una de las cuales, la situada en la torre del Homenaje, servía de oratorio. Al oeste se dispuso una sala y la escalera principal.

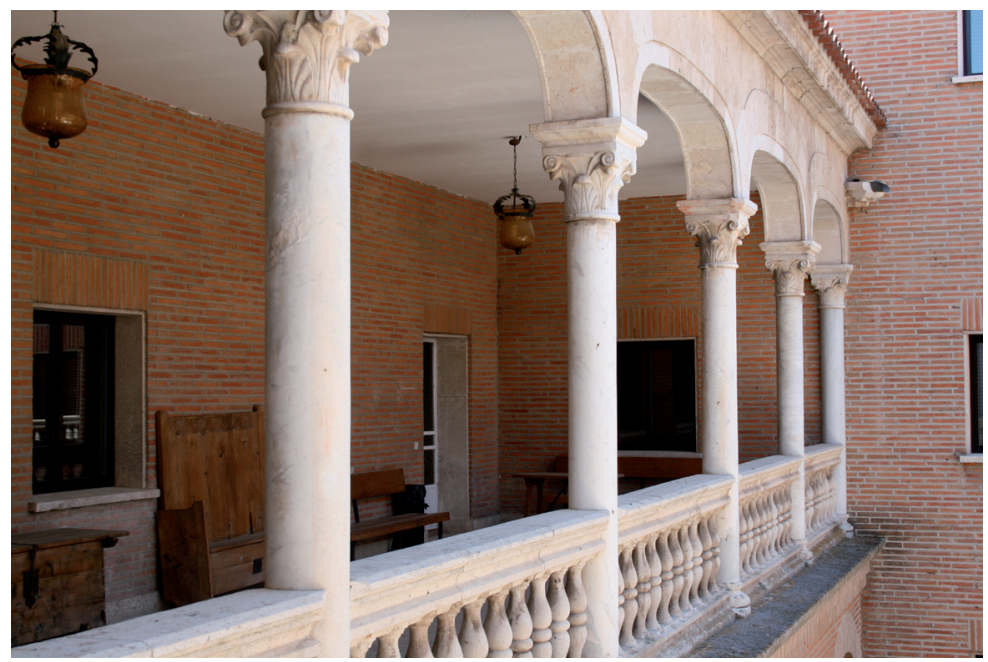

Fig. 6. Castillo de Coca. Columnas de mármol en el patio reconstruido.

El patio, rectangular, se componía de tres galerías dobles de columnas de Génova (seis en los lados largos y cinco en el corto), que servían de asiento a unos arcos cuya forma no se detalla en el documento (Figs. 5 y 6). Tampoco se conoce si se voltearon de piedra o de ladrillo y yeso, aunque la inexistencia de restos y las declaraciones de algunos testigos, que relatan cómo Antonio de Fonseca "labró toda la casa de yesería" o1 "fiço las paredes de yesería labrada del patyo" 92 , parecen indicar que se impusieron las formas del alarife hispalense y que las arcadas estarían posiblemente cubiertas de yesos, como en las sevillanas y más tardías de Pilatos, de las Dueñas y de Jerónimo Pinelo ${ }^{93}$. Dichas labores de yeso se combinaban con los azulejos que decoraban los arrimaderos de dichas logias. Estos arcos arrancaban sobre treinta columnas de mármol -de las que sólo se han conservado ocho-, que se integraron en el patio reconstruido en los años 50 del siglo pasado ${ }^{94}$. Sus capiteles, que extrañamente no se decoraron con las armas de los Fonseca, son de orden corintio pero muy simplificado, con dos filas de hojas de acanto, hélices y un ábaco cuadrado de lados rectos (Fig. 7)

91 ARChV, Pl. Civiles, Ceballos (F), C. 1124-1, 1ª pieza, Pero Vázquez.

92 Idem, declaración de Hernán Velázquez.

93 T. FALCÓN MÁRQUEZ, Casas sevillanas desde la Edad Media hasta el Barroco, Sevilla, 2012.

94 Son las ocho correspondientes a las exentas de las crujías este y oeste (las dos adosadas parecen producto de la restauración de los años 50), que se recuperaron en Olmedo e Íscar, según se aprecia en antiguas fotografías (F. RODRÍGUEZ MARTÍNEZ y D. RUBIO GALINDO, El castillo..., p. 73). En la restauración se añadieron 6 capiteles de "castañuelas" en el lado norte. 


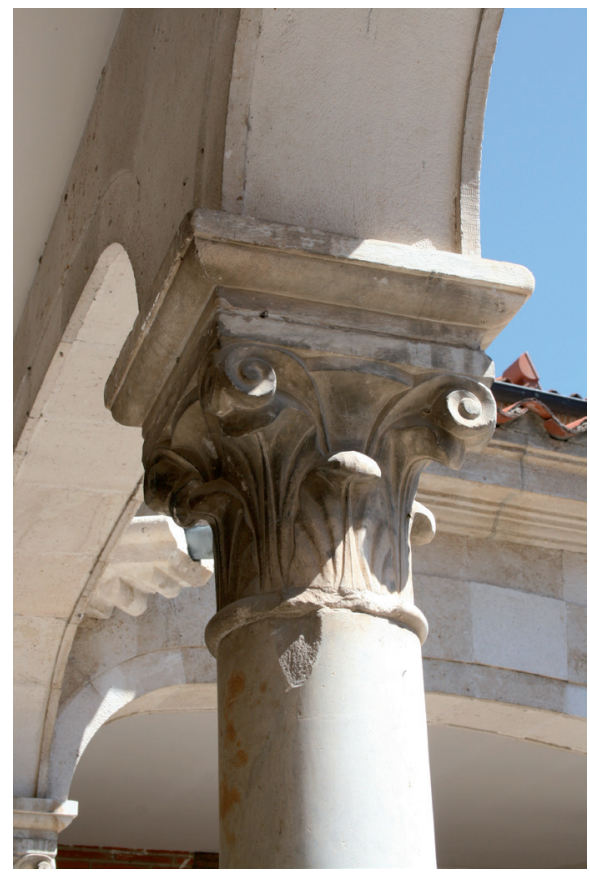

Fig. 7. Castillo de Coca. Capitel. Mármol.

En el centro del patio Antonio de Fonseca pretendió abrir un pozo, pero ante la imposibilidad de retener el agua por culpa del terreno arenoso donde se asienta el castillo habilitó un aljibe. Para ello tuvo que subir el nivel del patio varios escalones, solándolo nuevamente con losas de las canteras de San Miguel del Arroyo ${ }^{95}$

No acabaron aquí las reformas de Antonio. Sobre los adarves norte, oeste y sur del recinto interior levantó miradores, y en la Torre de la Prisión, un cenadero. Afortunadamente conservamos un grabado fidedigno del castillo ${ }^{96}$ (Fig. 8), previo al desmontaje de la zona palaciega ordenado por el duque de Berwick en $1828^{97}$. En él se observa con claridad el mirador que corría entre la torre del Homenaje y la de la Prisión: una larga logia de columnas de mármol ${ }^{98}$, que desembocaba en la terraza de la torre de la Prisión, donde se prolongaron en altura las garitas, entre las cuales se abrieron unos arcos que servían de apoyo a la armadura de cubierta que lo techaba ${ }^{99}$.

\footnotetext{
95 ARChV, P1. Civiles, Ceballos (F), C. 1124-1, 2ª pieza, Martín Gómez.

96 Alexandre Louis Joseph, CONDE DE LABORDE, Voyage pittoresque et historique de L'Espagne, París, 1806-1819, lámina XXVII.

97 P. MADOZ, Diccionario Geográfico-Estadístico-Histórico de España y sus posesiones de ultramar, Madrid, 1845-1850, (Edic. facsímil, Valladolid, 1984, t. 6, p. 60).

98 “...y en los miradores de la dicha fortaleza puso mármoles de Jénova traydos a mucha costa e gasto...”. ARChV, Pl. Civiles, Ceballos (F), C. 1124-1, $1^{\text {a }}$ pieza, Gonzalo Núñez.

99 “e subyó [Antonio de Fonseca] la torre del mirador desde el prençipyo de unos arquillos donde están çiertos mármoles de Génova o de alavastro, y cubrió la dicha torre de muy buen maderamiento". ARChV, Pl. Civiles, Ceballos (F), C. 1123-1, $5^{\mathrm{a}}$ pieza, Francisco de Nieva, herrero.
} 
Un mirador similar se habilitó en el paño oeste del recinto interior, sobre el río, donde también se instaló el correspondiente corredor de columnas de Carrara ${ }^{100}$; mientras que en el lado sur, "por la trasera del dicho quarto viejo que sale azia la çerca, [Antonio de Fonseca] le subió e cresçió de alvañería, y hechó unos antepechos de valaustras de piedra asta arriva con sus pilares mortidos de piedra" ${ }^{101}$.

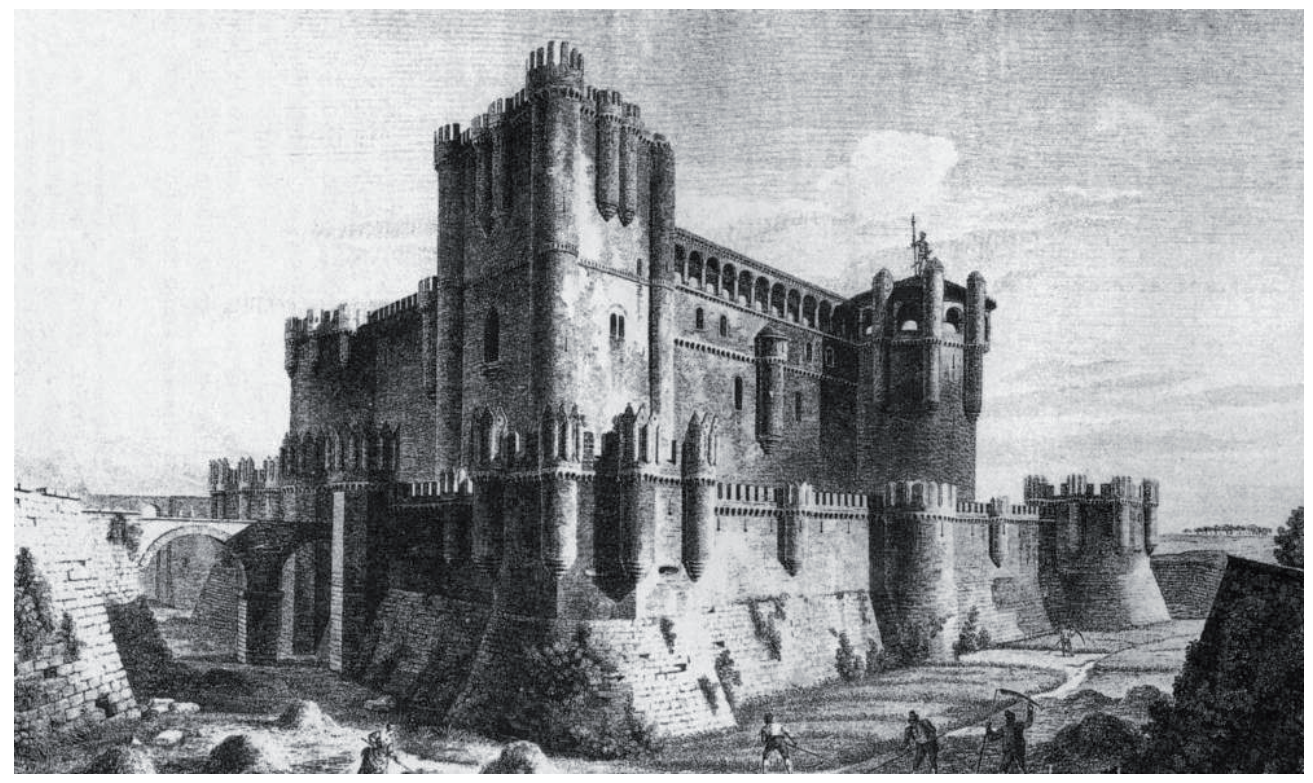

Fig. 8. Castillo de Coca. Grabado. Conde de Laborde. 1806-19.

El responsable de la obra fue, como ya he dicho, el sevillano Diego Rodríguez, a quien ayudaron un número indefinido de oficiales, principalmente de la misma vecindad $^{102}$, y el albañil local Antonio de Vallejo, hijo del Francisco de Vallejo que trabajó para Alonso de Fonseca, quien en su declaración se equiparó sin pudor con el andaluz: "que como maestro, juntamente con el dicho Diego Rodríguez, sevillano, labró en todas las dichas obras" ${ }^{103}$. En la carpintería de los tres cuartos del patio participó también el carpintero local Alonso de Navasdoro ${ }^{104}$, aunque para realizar las ventanas

100 “...e vio quel dicho Antonio de Fonseca hizo e hedificó la torre del homenaje, lo alto della questava para acabar... Y ansimismo hizo los miradores azia el rrío, y puso en ellos mármoles rricos, blancos, que dezían que se avían traydo de Jénova...". ARChV, Pl. Civiles, Ceballos (F), C. 1124-1, 2ª pieza, Fernando de Torres.

101 ARChV, P1. Civiles, Ceballos (F), C. 1124-1, 2 a pieza, declaración de Antonio Vallejo, carpintero que labró en la fortaleza.

102 Alonso García, tejero, dice que “...los maestros ... heran traydos de Sevilla y de otras partes para que labrasen". ARChV, Pl. Civiles, Ceballos (F), C. 1124-1, 1ª pieza.

103 ARChV, Pl. Civiles, Ceballos (F), C. 1124-1, $2^{\text {a }}$ pieza.

104 Todos los testigos encarecen la carpintería de los cuartos del patio que se realizó con vigas de Valsaín. ARChV, Pl. Civiles, Ceballos (F), C. 1124-1, $2^{\mathrm{a}}$ pieza. 
y asentar en ellas los mármoles que se habían traído de Génova, se solicitó la presencia del alarife vallisoletano Juan de Herrera, quien acudió a Coca con sus oficiales ${ }^{105}$.

Una cuestión pendiente en este relato es la datación de todas estas obras de Antonio de Fonseca. La primera noticia sobre la presencia de maestos sevillanos en Coca se fecha en 1512, cuando se pusieron como ejemplo para la contratación de otros alarifes de la misma vecindad para el castillo de Arévalo ${ }^{106}$. En buena lógica, esos albañiles sevillanos que labraban en Coca lo hacían desde el tiempo suficiente para que su labor fuera conocida y valorada por el alcaide de Arévalo, pues de otra manera no se explica que Juan Velázquez de Cuéllar, alcaide de la citada fortaleza ${ }^{107}$, mandase llamar a otros operarios sevillanos, a los que prometió la misma soldada que pagaba Fonseca: 4 reales diarios más 1 fanega de trigo al mes para el maestro, y 2 reales diarios para los oficiales, además de cama y posada. Por otro lado, la participación de Juan de Ruesga en la elaboración de las trazas marca la fecha post quem de 1506, momento en que comenzó su relación con Juan Rodríguez de Fonseca en la Catedral de Palencia. Pero si con estos datos se puede admitir sin excesivas reservas el inicio de los trabajos en el patio de Coca al finalizar la primera década del siglo XVI, más complicado resulta concretar la llegada de los mármoles. Para comprender la adquisición de esos materiales por Antonio de Fonseca debe recordarse no sólo su citado viaje a Italia de 1495, sino, sobre todo, la moda cortesana por la importación de mármoles genoveses destinados a los monumentos funerarios y a la composición de partes fundamentales de las casas y palacios durante las primeras décadas del siglo XVI.

Faltos en muchos casos de fuentes documentales para fechar dichas aportaciones para la arquitectura doméstica, se han realizado intentos de sistematizarlas y ordenarlas ${ }^{108}$. Fue el patio de La Calahorra el primero de la serie, producto de un cambio de planes que supuso a partir de 1509 la sustitución de Lorenzo Vázquez de Segovia por el genovés Michele Carlone como director de la obra y el empleo de columnas de mármol de Carrara para las galerías altas del patio ${ }^{109}$. Junto a éste, el coetáneo castillo

105 Idem. Declaración de Alonso de Navasdoro. Este Juan de Herrera, carpintero y alarife vallisoletano, nacido hacia 1478, fue el carpintero principal del palacio de los condes de Benavente en Valladolid, comenzado en 1516. L. VASALLO TORANZO, "La casa del conde de Benavente en Valladolid, un frustrado palacio al servicio de Carlos V", en V. Mínguez (ed.), Las artes y la arquitectura ..., p. 811.

106 E. Cooper, ob. cit., v. I.1., pp. 196-7.

107 Sobre este importante personaje de la corte de los Reyes Católicos, sobre el que se volverá más abajo, M. DIAGO HERNANDO, "El Contador Mayor Juan Velázquez de Cuéllar: ascenso y caída de un influyente cortesano en la Castilla de comienzos del siglo XVI", Cuadernos de Historia de España, 83 (2009), pp. 157185 .

108 Para España, con toda la bibliografía anterior, F. MARÍAS, "La magnificencia del mármol. La escultura genovesa y la arquitectura española (siglos XV y XVI)", en P. BOCCARDO, J.L. COLOMER y C. de FABIO (dirs.), España y Génova. Obras, artistas y coleccionistas, Madrid, 2004, pp. 60 y ss. Para Valencia, L. ARCINIEGA GARCÍA, "El Mediterráneo como soporte de intercambios culturales", en El comercio y el Mediterráneo. Valencia y la cultura del Mar, Valencia, 2006, pp. 37-65. Para Andalucía, T. FALCÓN MÁRQUEZ, "Mármoles de talleres genoveses en las casas-palacio de Andalucía occidental en el siglo XVI", en R. CAMACHO MARTÍNEZ, E. ASENJO RUBIO y B. CALDERÓN ROCA (coords. y edts.), Creación artística y mecenazgo en el desarrollo cultural del Mediterráneo en la Edad Moderna, Málaga, 2011, pp. 445-478.

109 F. MARÍAS, "Sobre el castillo de La Calahorra y el Codex Escurialensis", Anuario del Departamento de Historia y Teoría del Arte, 2 (1990), pp. 117-129; M.A. ZALAMA, El palacio de La Calahorra, Granada, 
de Vélez Blanco se ha considerado proyectado por maestros españoles y labrado en mármol local por artistas italianos ${ }^{110}$. A partir de estas dos obras, o mejor, de la primera -aunque debe citarse aquí la de Vélez Blanco por las similitudes que presenta con Coca (participación de tracistas hispanos, existencia de un cuarto cerrado en el patio adornado con ventanas de mármol, significativa presencia, al igual que en La Calahorra, de azulejos, importancia del mirador...)-, se multiplican las importaciones de columnas y de otros elementos arquitectónicos de Génova.

La zona peor estudiada ha sido la castellana, donde durante las tres primeras décadas del XVI, además de en Coca, se asentaron mármoles italianos en Toledo (actual Seminario Menor) ${ }^{111}$, Salamanca (casa de las Conchas del doctor Rodrigo Maldonado de Talavera, antes de 1517) ${ }^{112}$, Toro (casa de Juan Rodríguez de Fonseca, antes de 1524) ${ }^{113}$, Villarejo de Salvanés (patio de la fortaleza promovido por Hernando de Vega, Comendador Mayor de Santiago, en 1515) ${ }^{114}$ y Madrid (Casa de Campo de Francisco de Vargas, antes de $1519^{115}$, y casa del tesorero Alonso Gutiérrez de Madrid, hacia $1530^{116}$ ).

Pero si de la mayoría de dichos patios y galerías se desconoce su datación exacta, tampoco se sabe en qué momento se encargaron las columnas y ventanas de Coca, ni cuándo se enviaron desde Génova, ni si se trató de un solo envío o de varios. Una reciente noticia pone a los Fonseca en relación con los talleres genoveses en la temprana fecha de $1513^{117}$. Entonces, el rey Fernando encomendó a Antonio de Fonseca, Juan Rodríguez de Fonseca y Juan Velázquez de Cuéllar la ejecución del sepulcro donde habrían de descansar la reina católica y él. Aunque la presencia de Velázquez estaba justificada por su intervención anterior en el monumento del príncipe don Juan, obra

1990; C. MORTE GARCÍA, "Pedro de Aponte en Bolea. Y una noticia de La Calahorra (Granada)", Boletín del Museo e Instituto "Camón Aznar", LXVII (1997), pp. 95-122 y F. MARÍAS, "El Codex Escurialensis. Problemas e incertidumbres de un libro de dibujos de antigüedades del último quattrocento", Reales Sitios, 163 (2005), pp. 14-35.

110 O. RAGGIO, "The Vélez Blanco Patio. An Italian Renaisance Monument from Spain", The Metropolitan Museum of Art Bulletin, XXIII, 4 (1964), pp. 141-176. (Traducción en "El patio de Vélez Blanco. Un monumento señero del Renacimiento", Anales de la Universidad de Murcia, XXVI, 2-3 (1969), pp. 231-261). M. FERNÁNDEZ GÓMEZ, "Hacia una recuperación del palacio de Vélez Blanco (Almería): Los órdenes en la arquitectura española del protorrenacimiento", Fragmentos, 8-9, pp. 78-89.

111 R. DÍEZ DEL CORRAL GARNICA, Arquitectura y mecenazgo. La imagen de Toledo en el Renacimiento, Madrid, 1987, pp. 170-2.

112 L. VASALLO TORANZO, "Rodrigo Maldonado de Talavera y la Casa de las Conchas", La arquitectura tardogótica castellana entre Europa y América, Madrid, 2011, p. 165.

113 Se trata de las columnas tradicionalmente asociadas por la historiografía a la promoción de Alonso de Fonseca, obispo de Osma, en el claustro chico del convento de San Francisco de dicha ciudad (hoy en su mayoría en una casa particular), cuando en realidad pertenecieron a la casa de Juan Rodríguez de Fonseca, como declaran los escudos de sus capiteles.

114 J.M. de AZCÁRATE, "Datos sobre las construcciones en el priorato de Uclés durante la primera mitad del siglo XVI", BSEAA, XXV (1959), pp. 96 y 153 y ss.

115 F. MARÍAS, "De Madrid à Paris: François I Ir et la Casa de Campo", Revue de l'Art, 91 (1991), p. 31.

116 M. ESTELLA, "Artistas madrileños en el palacio del Tesorero (Descalzas Reales), el palacio de Pastrana y otros monumentos de interés", AEA, LVIII (1985), pp. 54-6; M.Á. TOAJAS ROGER, "Capiteles del primer Renacimiento en las Descalzas Reales de Madrid: estudio del patio del Tesorero", Anales de Historia del Arte, 13, 2003, pp. 97-130.

117 M.J. REDONDO CANTERA, "La intervención de Felipe Bigarny en el sepulcro de los Reyes Católicos", Pulchrum. Scripta varia en honorem $M^{a}$ Concepción García Gainza, Navarra, 2011, pp. 684-689. 
de Doménico Fancelli -el mismo escultor al que se confió éste de los reyes-, todo parece indicar que en realidad fueron los hermanos Fonseca quienes se ocuparon del seguimiento de la obra. Así al menos lo apunta la participación de Maestre Martín, personaje íntimamente ligado al obispo de Palencia, para dar ciertas "muestras" en 1514 para los bultos que se hacían en Génova, y la existencia de unas "medallas de yeso con las figuras del rey e de la reyna" en Coca a la muerte de Antonio de Fonseca, que pueden relacionarse con el modelo o "medalla" que sabemos realizó Bigarni de Fernando el Católico para enviarlo a Italia.

No es posible afirmar con rotundidad que dicha encomienda a los Fonseca obedeciese a un conocimiento previo por su parte del mercado marmóreo italiano, pero al igual que la presencia de Velázquez se explica por su experiencia anterior en el sepulcro del príncipe, se podrían aceptar similares motivaciones en el caso de los Fonseca y admitir una conexión previa de estos con los mecanismos de la importación del mármol genovés a España, que podría remontarse a los años inmediatos al inicio de la obra del patio del castillo de Coca, es decir en torno a 1510 o poco después. 